\title{
Implementasi Programable Logic Control Dan Wonderware Intouch Untuk Otomasi Smart Home
}

\author{
Sarifuddin, Nur Yanti \\ Teknik Elektronika Industri \\ Politeknik Negeri Balikpapan \\ Jl. Soekarno Hatta Km. 8 Balikpapan \\ muhammadsarifuddin21@gmail.com \\ nur_yantis@yahoo.com
}

\begin{abstract}
The development of technology in the field of automation today, allows humans to create an automatic control system that is monitored in order to provide all the comfort, safety, security and energy savings in the home. it requires a control system programmed through a computer that controls almost all of the equipments in home.

With smart home control center using a PLC (Programmable Logic Control) Omron CPMIA 30 CDR. This has a smart home control lighting system using LEDs for lighting inside and outside home, security systems function in the accident of theft by using magnetic door sensor and PIR with alarm indication, then to the security system of a gas leak using MQ6 used in the accident of a gas leak especially LPG gas with shutdown output system that has function for the security in home, Smart home automation system is only using a sensor LDR when dark / night light automatically turns on terrace home and the smart socket to control appliances in the smart home using a miniature fan and TV. This control can be done with dual systems that by manual system using deep switch and the remote system using the SCADA HMI (Human Machine Interface). HMI here is using Wonderware Intouch software that has functions as a liaison between the human (operator) with a smart home appliance via a computer or smart Phone. By using smart home system is capable of providing many benefits and advantages to the home owner in the future in terms of energy, cost and effort.
\end{abstract}

Keywords : Smart Home, Programable Logic Control, Wonderware Intouch

\begin{abstract}
Abstrak
Perkembangan teknologi dalam bidang otomasi saat ini, memungkinkan manusia untuk menciptakan suatu sistem kontrol otomatis yang termonitor guna memberikan segala kenyamanan, keselamatan, keamanan dan penghematan energi didalam suatu rumah. Untuk itu dibutuhkan sistem kontrol yang terprogram melalui sebuah komputer yang mengendalikan hampir semua perlengkapan dan perlatan rumah.

Dengan Pusat pengontrolan smart home menggunakan PLC (Programmable Logic Control) Omron CPMIA 30 CDR. Dalam smart home ini terdapat pengontrolan sistem lighting menggunakan LED untuk penerangan di dalam dan luar rumah, sistem keamanan berfungsi apabila terjadi kemalingan dengan mengunakan sensor magnetic door dan PIR dengan indikasi alarm, kemudian untuk sistem keamanan dari kebocoran gas menggunakan MQ6 yang digunakan jika terjadi kebocoran gas khususnya gas LPG dengan output shutdown system yang berfungsi untuk mengamankan suatu rumah, sistem otomasi dalam smart home ini hanya mengunakan sensor LDR ketika gelap/malam hari lampu teras rumah menyala secara otomatis dan smart socket untuk kontrol peralatan rumah dalam smart home ini mengunakan miniature kipas dan TV. Pengontrolan ini dapat dilakukan dengan dual sistem yaitu dengan sistem manual mengunakan deep switch dan sistem remote dengan mengunakan SCADA HMI (Human Machine Interface). HMI disini mengunakan software Wonderware Intouch yang berfungsi sebagai penghubung antara manusia (Operator) dengan alat smart home melalui sebuah computer atau smart Phone. Dengan mengunakan sistem smart home ini mampu memberikan banyak manfaat dan keuntungan kepada pemilik rumah kedepanya dari segi energi, biaya dan tenaga.
\end{abstract}

Kata kunci : Smart Home, Programable Logic Control, Wonderware Intouch 


\section{Pendahuluan}

Perkembangan teknologi dalam bidang otomasi saat ini, memungkinkan manusia untuk menciptakan suatu sistem kontrol otomatis yang termonitor guna memberikan segala kenyamanan, keselamatan, keamanan dan penghematan energi pada suatu rumah. Untuk itu dibutuhkan sistem kontrol yang terprogram melalui sebuah komputer yang mengendalikan hampir semua perlengkapan dan peralatan rumah. Mulai dari pengaturan tata lampu, berbagai alatalat rumah tangga dan sistem keamanannya yang dapat dikontrol melalui kendali jarak jauh (Remote) sehingga rumah bisa diawasi dan dikontrol sesuai dengan keingininan pemilik rumah.

Dengan menggunakan PLC

(Programmable Logic Control) sebagai controller dan Wonderware Intouch sebagai SCADA (Supersivory Control and Data Aqcusition) akan menunjang otomasi smart home agar sistem kerja yang lebih efektif dan efisien yang mampu mengontrol melalui kendali jarak jauh dengan mengunakan sebuah computer dan Smart Phone yang memberikan indikasi/informasi kondisi suatu rumah kepada pemilik. Di smart home ini terdapat sensor-sensor sebagai sistem keamanan dan pengontrol secara otomatis. Teknologi smart home ini mampu memberikan banyak manfaat dan keuntungan kepada pemilik rumah kedepanya dari segi energi, biaya dan tenaga.

\section{Metoda Penelitian}

Metoda yang digunakan dalam penelitian ini berasal dari tinjauan pustaka, perancangan dan pembuatan prototype smart home, pemrograman PLC dan HMI sebagai SCADA dalam aplikasi pengontrolan smart home, trial and error dalam simulasi prototype.

\section{Hasil Penelitian}

Sistem rumah cerdas (Smart Home) adalah sistem aplikasi yang merupakan gabungan antara teknologi dan pelayanan yang dikhususkan pada lingkungan rumah dengan fungsi tertentu yang bertujuan meningkatkan efesiensi, kenyamanan dan keamanan penghuninya. Sistem rumah cerdas biasanya terdiri dari perangkat kontrol, monitoring dan otomatisasi beberapa perangkat atau peralatan rumah yang dapat diakses melalui sebuah komputer.

Sistem rumah cerdas adalah sistem yang terdiri dari beberapa komponen pendukung yang saling berinteraksi satu sama lain. Sebuah rumah dapat dikatakan sebagai Smart Home apabila memiliki komponen personal internal networking, intellegent control dan home automation.

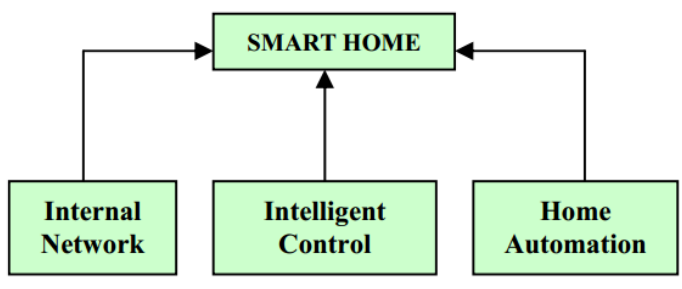

Gambar 1. Komponen Smart Home

\section{PLC OMRON CPM1A}

PLC Omron CPM1A merupakan salah satu tipe PLC yang memiliki kecepatan yang tinggi yang dirancang untuk operasi kontrol yang memerlukan jumlah I/O dari 10 sampai 100 buah I/O. Selain itu, PLC ini memiliki kemudahan dalam penginstalan, pengembangan, dan pemasangan sistem.

Setiap PLC yang digunakan memiliki spesifikasi khusus yang dijadikan pedoman dalam pengaplikasiannya. Berikut ini adalah tabel spesifikasi khusus PLC Omron CPM1A 30 CDR. 
CPM1A-30CDR- $\square / 30 C D T-\square / 30 C D T 1-\square$ CPU Unit
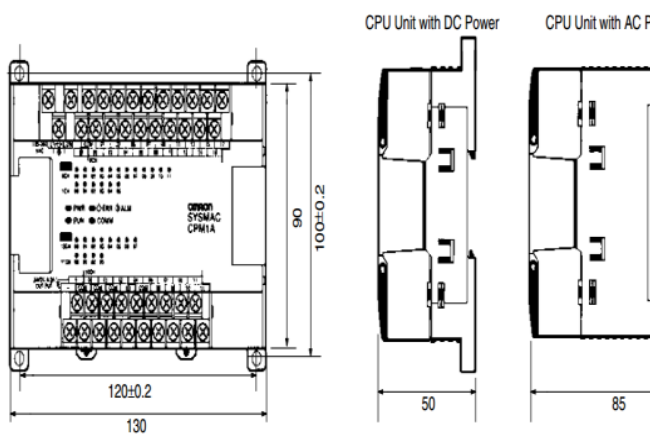

Gambar 2. Dimensi Omron CPM1A (30 CDR)

\section{SCADA (Supersivory Control and Data Aqcusition)}

SCADA (Supersivory Control and Data Aqcusition) adalah sistem yang memungkinkan pengguna untuk melakukan:

1. Monitoring (Pengawasan).

2. Controlling (Pengendalian).

3. Data acquisition (pengambilan dan

perekaman data).

Ketiga fungsi diatas dapat dipenuhi dengan mewujudkan dalam bentuk hardware maupun software. Salah satu software SCADA yang paling banyak digunakan di dunia ialah wonderware. Software utama yang digunakan dalam sistem SCADA yaitu Intouch yang befungsi sebagai HMI (Human machine Interface). Istilah HMI muncul untuk menjebatani jurang antara manusia (operator) dengan mesin (plant), sehingga operator dapat mengawasi dan mengendalikan Plant dengan mudah.

Sistem yang dapat melakukan pengawasan, pengendalian, dan akuisi data terhadap sebuah plant. Dalam terminologi kontrol, supervisory control sering mengacu pada kontrol yang tidak langsung, namun lebih pada fungsi pengawasan. Dengan kata lain, pengendali utama tetap dipegang oleh PLC (atau pengendali lainnya) kontrol SCADA hanya bersifat koordinatif dan sekunder.

\section{Wonderware Intouch}

Program SCADA yang digunakan adalah "Wonderware InTouch 9.0", yang merupakan salah satu komponen dari "Wonderware Factory Suite" untuk HMI (Human Machine Interface). Berikut ini rancangan mengunakan Wonderware InTouch 9.0 :

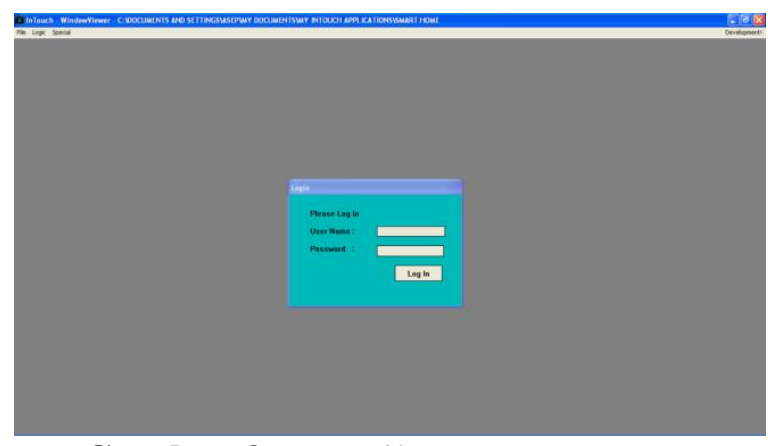

Gambar 3. Tampilan Log In HMI

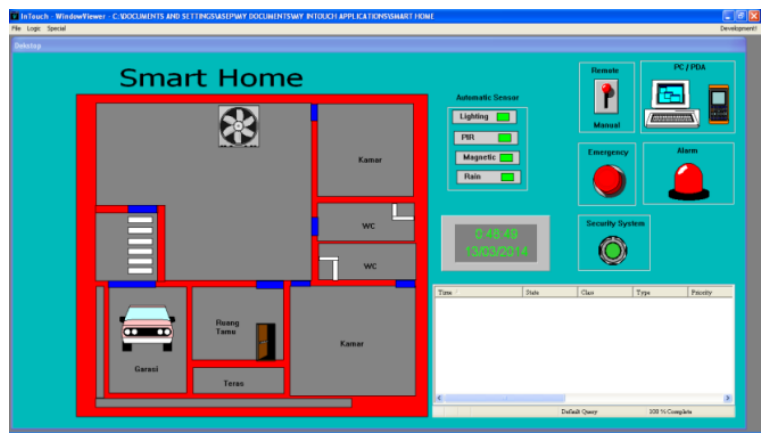

Gambar 4. Tampilan Kontrol HMI

\section{CX-Programmer}

$C X$ - Programmer merupakan sebuah perangkat lunak Produksi Omron Corporation yang berguna sebagai pembuat Diagram Leadder. $C X-$ Programmer yang digunakan adalah Versi 9.2 Program ini dapat digunakan untuk PLC Omron $C$ series, $C V$ series, dan $S R$ series. 


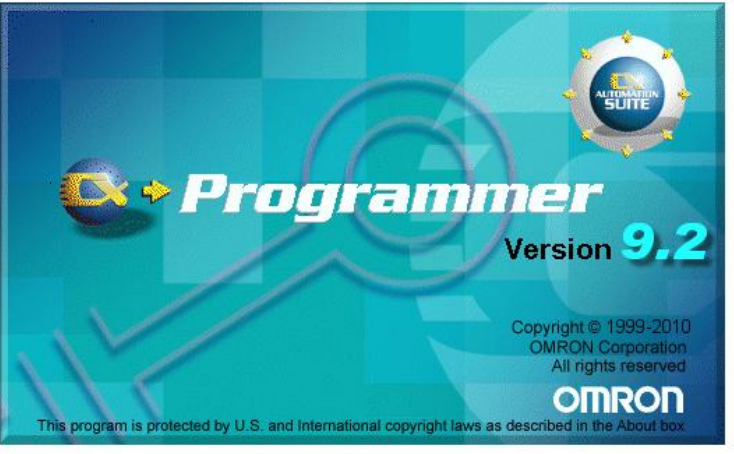

Gambar 5. CX- Programmer 9.2

\section{Diagram Blok Smart Home}

Rangkaian antar muka ini digunakan untuk pengendalian antara PLC (Programmable Logic Control) dengan input : Dip switch, sensor Magnetic door, LDR, PIR dan MQ6. Output : LED, Buzzer dan Smart socket. Dalam sistem Smart home ini mengunakan HMI (Human Machine Interface) sebagai tempat pengontrolan secara remote dan Dip switch sebagai kontrol manual. Diagram bloknya smart home pada gambar 5 .

Prinsip kerja dari masing-masing komponen Blok Diagram diatas yaitu :

1. Dip switch berfungsi sebagai input PLC dengan kendali manual untuk sistem penerangan dan peralatan pada smart home .

2. Sensor LDR berfungsi sebagai input PLC sebagai kontrol penerangan otomatis ketika gelap atau malam hari.

3. Sensor MQ 6 berfungsi sebagai input PLC yang mendeteksi jika terjadi kebocoran Gas LPG dan memberikan indikasi pada HMI dan alarm.

4. Sensor PIR berfungsi sebagai input PLC yang mendeteksi gerakan jika terjadi penyusup masuk dan memberikan indikasi pada HMI dan alarm .

5. Sensor Magnetic door berfungsi sebagai input PLC yang mendeteksi jika pintu di buka paksa atau seseorang masuk tanpa izin kemudian memberikan indikasi pada HMI dan alarm.

6. PLC sebagai (Controller) pusat pengendalian yang memproses input dan menghasilkan output sesuai program.

7. Power supply berfungsi sebagai sumber tegangan PLC.

8. Rangkaian LED sebagai penerangan pada Smart home.

9. Relay berfungsi sebagai switch untuk menghubungkan tegangan 24V ke input PLC.

10. Rangkaian alarm befungsi sebagai indikator suara jika terjadi bahaya.

11. Smart socket befungsi sebagai stop Contact yang dapat dikontrol sehingga dapat menghemat daya pemakaian pada rumah.

12. TV sebagai peralatan rumah yang akan dikontrol.

13. Kipas sebagai Pendingin ruangan.

14. PC dan Smart Phone berfungsi sebagai remote secara HMI.

15. HMI berfungsi sebagai tempat pengontrolan berbentuk visual gambar untuk memudahkan dalam proses pengontrolan. 


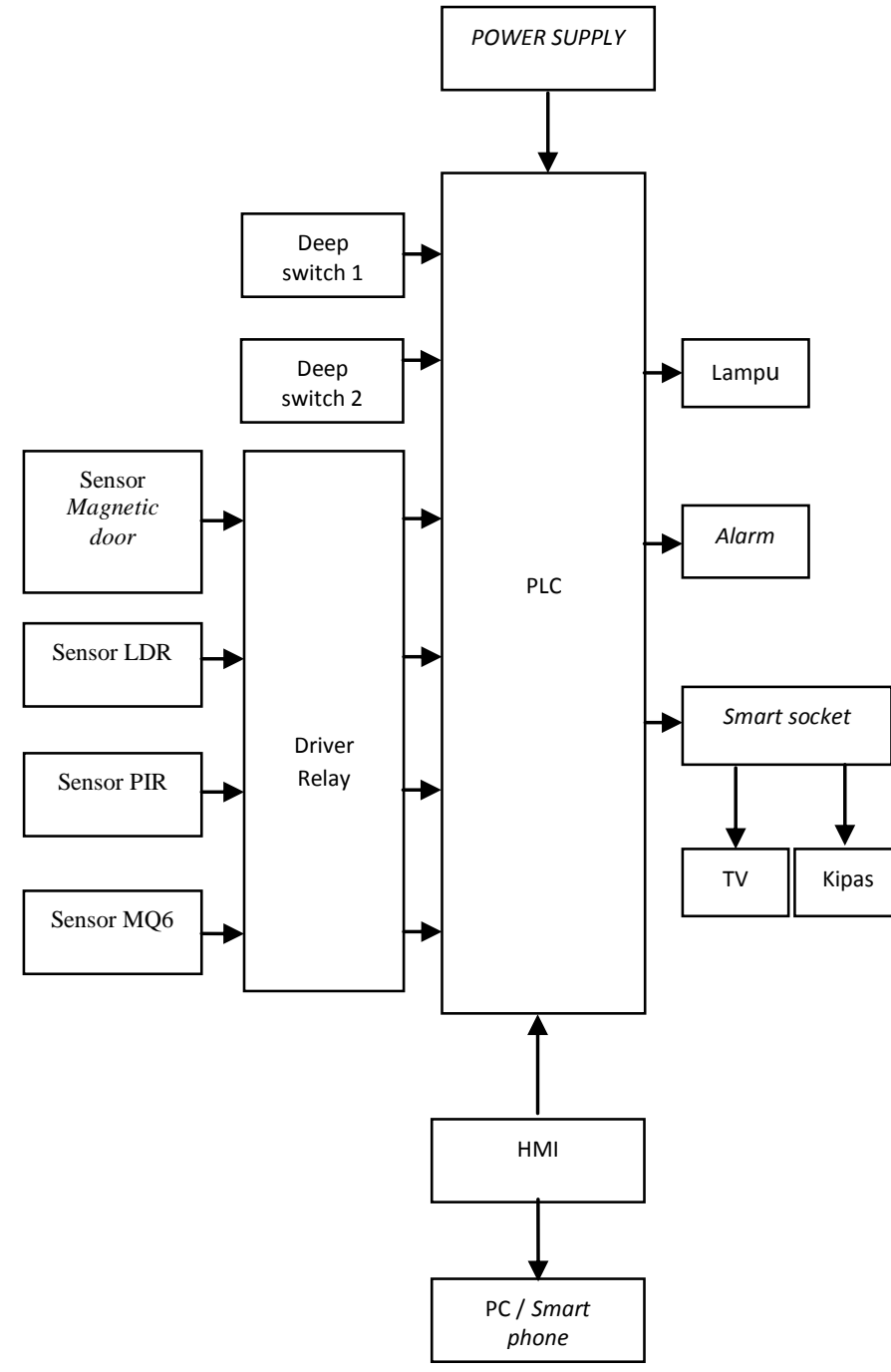

Gambar 5. Diagram blok Smart Home

\section{Sistem Kerja Smart Home}

Sistem kerja flow chart diatas adalah pengguna harus Log In terlebih dahulu dengan User Name dan Password yang sudah didaftarkan. Masuk ketampilan HMI, pilih antara kontrol Remote dengan kontrol manual. Kontrol remote dan manual terdiri dari 3 sistem kontrol yaitu lighting system, smart socket, dan security system. Bedanya antara kontrol remote dan kontrol manual ialah dalam sistem pengaktifannya. Kontrol remote dilakukan dengan HMI atau interface sedangkan sistem pengaktifan kontrol manual dengan cara mengaktifkan dip switch pada smart home. Selanjutnya Smart socket berfungsi sebagai pengontrol alat-alat yang ada di rumah sehingga dapat mengurangi pengunaan daya listrik.
Untuk Lighting system dapat dilakukan secara kontrol remote dan manual. Untuk sistem kontrol automatis Lighting system smart home ini mengunakan Sensor LDR jika mendeteksi gelap maka lampu teras rumah menyala automatis. Security system berfungsi sebagai sistem keamanan pada rumah. Security system ini memiliki sensor-sensor seperti sensor gas MQ6, magnetic door dan PIR. Jika salah satu sensor tersebut diaktifkan dan terdeteksi maka alarm akan berbunyi dan informasi alarm akan aktif dan ditampilkan pada HMI. Khusus untuk security system mengunakan sensor gas MQ6 ketika mendeteksi kebocoran gas LPG maka akan terjadi Shutdown system.

\section{Kesimpulan}

Berdasarkan hasil penelitian dan pembahasan yang telah dilakukan maka dapat diambil kesimpulan sebagai berikut:

a. Smart Home yang telah dirancang mengunakan PLC Omron CPM1A 30 CDR

sebagai pusat controller.

b. Smart home ini dilengkapi dengan SCADA HMI ( Human Machine Interface ) untuk memudahkan dalam pengendalian dan pengawasan melalui sebuah computer atau smart phone.

c. Dalam perancangan smart home ini pengendalian dapat dilakukan dengan dual sistem yaitu dengan sistem manual dan remote.

d. Smart home ini mempunyai lighting system sebagai sistem pencahayaan rumah dan smart socket yang berfungsi sebagai control peralatan rumah.

Smart home ini juga mempunyai sistem otomasi sebagai kontrol automatis dan sistem pengamanan jika terjadi kondisi

e. bahaya seperti kemalingan dan kebocoran gas dengan reaksi menyalakan sebuah alarm dan shutdown system. 


\section{Saran}

Untuk mengembangkan sistem smart home ini dapat digunakan : solenoid, sensor-sensor gas jenis lain, dan motor penggerak lain yang memiliki kecepatan yang lebih tinggi dan menyediakan supply cadangan agar jika terjadi pemadaman listrik sistem tetap dapat beroperasi khusunya computer dan PLC sebagai pusat controller.

\section{Daftar Pustaka}

Wicaksono,Handy. 2011. SCADA Software dengan Wonderware Intouch, Keputih : Graha Ilmu.

Depari, Ganti. 1992. Teori Rangkaian Elektronika, Bandung : CV. Sinar Baru.
Malvino, Albert Paul. 1989. Prinsipprinsip Elektronika. Jakarta: Erlangga.

Hamdani. Aplikasi Smart system pada gedung Perkantoran dengan mengunakan PLC FXOS-30MR. Universitas Sumatra Utara. 2009.

Tri Fajar Yurmama S dan Novi Azman, Perancangan Software Aplikasi Pervasive Smart Home. Yogyakarta. 20 Juni 2009.

Setiawan, Iwan. Buku Ajar Sensor dan Transduser. Universitas Diponegoro. Semarang, 2009.

Ruri Hartika Zain,Jurnal Teknologi Informasi dan Pendidikan ISSN : 2086 4981VOL. 6 NO. 1 Maret 2013 